Article

\title{
An Economic Analysis of Demand Side Management Considering Interruptible Load and Renewable Energy Integration: A Case Study of Freetown Sierra Leone
}

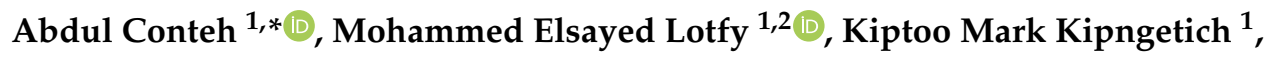 \\ Tomonobu Senjyu ${ }^{1}$, Paras Mandal ${ }^{3}$ (D) and Shantanu Chakraborty ${ }^{4}$ (D) \\ 1 Department of Electrical and Electronics Engineering, University of the Ryukyus, Okinawa 903-0213, Japan; \\ mohamedabozed@zu.edu.eg (M.E.L.); kiptoo.k.mark@gmail.com (K.M.K.); \\ b955542@tec.u-ryukyu.ac.jp (T.S.) \\ 2 Department of Electrical Power and Machines, Zagazig University, Zagazig 44519, Egypt \\ 3 Department of Electrical and Computer Engineering, University of Texas, El Paso, TX 78712, USA; \\ pmandal@utep.edu \\ 4 Energy Transition Hub, Australian-German Climate and Energy College, University of Melbourne, \\ Melbourne 3010, Australia; shantanu.chakraborty@unimelb.edu.au \\ * Correspondence: abdulreiche@gmail.com
}

Received: 1 April 2019; Accepted: 12 May 2019; Published: 17 May 2019

\begin{abstract}
Like in most developing countries, meeting the load demand and reduction in transmission grid bottlenecks remains a significant challenge for the power sector in Sierra Leone. In recent years, research attention has shifted to demand response (DR) programs geared towards improving the supply availability and quality of energy markets in developed countries. However, very few studies have discussed the implementation of suitable DR programs for developing countries, especially when utilizing renewable energy (RE) resources. In this paper, using the Freetown's peak load demand data and the price elasticity concept, the interruptible demand response (DR) program has been considered for maximum demand index (MDI) customers. Economic analysis of the energy consumption, customer incentives, benefits, penalties and the impact on the load demand are analyzed, with optimally designed energy management for grid-integrated battery energy storage system (BESS) and photovoltaic (PV)-hybrid system using the genetic algorithm (GA). Five scenarios are considered to confirm the effectiveness and robustness of the proposed scheme. The results show the economic superiority of the proposed DR program's approach for both customers and supplier benefits. Moreover, RE inclusion proved to be a practical approach over the project lifespan, compared to the diesel generation alternative.
\end{abstract}

Keywords: demand response; interruptible load; price elasticity; renewable energy; photo-voltaic; battery energy storage system

\section{Introduction}

Achieving the sustainable energy objectives for all (SEforALL) by universal access to modern energy efficiency approach is an essential component for economic development. According to the United Nations Sustainable Development Goal No.7, energy security is pivotal to economic development, access to energy will enable the small-and large-scale business to thrive, and utilities can function efficiently [1,2]. An extensive review of the socio-environmental sustainability benefits of renewable energy (RE) integration, especially for developing economies, is given in [3]. The study 
identified several opportunities that surround RE incorporation such as improved energy security, better accessibility, climate change mitigation and improved socio-economic development. Access to electricity in Sierra Leone is constrained to a small cross-section of the population, and it is estimated to be less than $15 \%$ of approximately 7 million people, with the capital city (Freetown) accounting for a significant proportion of electricity consumption. The energy sector in Sierra Leone is severely challenged with limited generation capacity, ageing, and overloaded transmission and distribution network. Due to the intermittent power supply from the grid, privately owned diesel or petrol generators, which are estimated at a cost of $U S \$ 300$, are often used by companies to supplement the dire needs for electricity supply. However, the running cost at which these companies operate becomes exorbitant, and often their services and products within the country go for higher costs $[4,5]$.

Ref. [6] enlists all generating facilities and their locations across the country with a total state-owned installed capacity of $130 \mathrm{MW}$. Recently, $50 \mathrm{MW}$ of additional power produced by an IPP (Karpower) was injected into the grid. In [7], a proposed $57 \mathrm{MW}$ thermal plant would be financed by the African Development Bank (AFDB), World Bank and other donor agencies targeted for Freetown electricity demand. At the moment the government has prioritized the improvement of the power industry to carter for the country's energy needs, a cocktail of interventions is being pursued, and this has been backed up with actions such as the budgeted US $\$ 15$ million for procurement, restructuring and general overhauling in 2015 [8]. Furthermore, the government has taken credible steps towards improving the current electricity situation across all the stages from generation to distribution. [9] highlights the restructuring of the energy sector in Sierra Leone which has to lead to the decentralization of the National Power Authority (NPA) into separate companies, i.e., the Electricity Distribution and Supply Authority (EDSA) and the Electricity Generation and Transmission Company (EGTC). The restructuring of the energy sector has facilitated competition amongst the IPP into the energy market especially in the capital Freetown, where the load demand is increasing at an exponential rate, and there is a significant deficiency in generation capacity to meet this growing demand especially for the maximum demand index (MDI) and some residential consumers. Despite all these efforts, the Sierra Leone energy sector is still faced with inadequate power generation and weak transmission network; hence, flattening of the load curve in Freetown, through RE integration and consumer participation, has long been acknowledged by the EDSA policymakers as an efficient technique for reducing the electricity production cost. Optimal RE integration is seen as a flexible way of achieving GHG abatement in the planned transition to a carbon-constrained future while meeting the load demand. However, according to [6] achieving both objectives have posed enormous challenges especially for developing countries in that, investing in state-of-the-art RE technologies usually comes with huge initial costs. The authors in [6] have attempted to present a multi-criteria optimal planning approach towards meeting the national net load demand of approximately $700 \mathrm{MW}$ for Sierra Leone in an economic and sustainable manner using different RE technologies, while achieving a significant reduction in GHG emission for the recommended hybrid system (photovoltaic (PV), wind, biomass, battery energy storage system (BESS), Diesel). In [10], the authors proposed the need for optimal sizing of rooftop and ground-mounted grid-connected PV panels and BESS on government buildings in a bid to reduce the supply deficit in the capital, Freetown. However, the authors did not consider demand-side management, through the implementation of demand response (DR) program towards changing the consumers' load demand pattern for improved supply reliability; and the attendant's techno-economic challenges of the existing grid.

In [11], the techno-economic challenges of large-scale RE sources integration considering the security of the existing grid facility and reliability of supply, for weak grids of developing countries, have been succinctly reviewed and analyzed. The problems of RE intermittent output and voltage stability are the key challenges of renewable energy deployment especially for an insufficient grid network. Increase in load demand at a rate not proportionate to the available generation and transmission capacity will compromise system reliability and resiliency. Hence, for intermittent RE generation to augment these problems, optimal energy management schemes are required. In recent 
years, a popular methodology used to balance supply and demand on the grid, particularly during times of peak load demand, is achieved by changing the demand pattern rather than increasing the supply; this practice is known as "demand response". According to [12], implementation of DR programs can result in shift peak demand, enhance system reliability, reduce transmission bottleneck and highly priced energy bills by shifting or re-adjusting consumption patterns. It can also reduce the effects of intermittent RE generation since the capacity of introduced RE sources will be optimally minimal, and the consumer can also be encouraged to embark on self RE generation and sell self-produced excess energy to the grid. Many authors have carried out research works on effective demand side management (DSM) approach for motivating consumers to modify their demand profile optimally. Researchers have adopted various DSM measures over time; literature [13] gave an extensive analysis of DSM implementations in the industrial sector and highlighted some of the challenges in the implementation of these programs. The authors in [14] presented feasible investment models for energy efficiency and DSM for IPP for various markets and attempted to evaluate the effect of RE penetration on the investment model. A two-level optimization approach DSM was executed utilizing the particle swarm optimization in [15]. The installation cost of the static var compensator, electric vehicle, PV was optimized under the condition that gives the best reactive power incentive to the participating customers towards achieving zero net energy homes. Some of the various DSM measures that have been employed by researchers includes interruptible load agreements; this special tariff is reciprocally advantageous yet, it does not distinctly indicate whether the customer benefit is equivalent to the value they provide to the utility [16]. Execution of DSM programs are yielding promising results in some countries such as in the European Union (EU) [17], Kuwait [18], China [19], South Africa [20], Finland [21] etc. In the United State, DR inclusion in the wholesale markets expanded by roughly $3 \%$ from 2016 to 2017 , to a sum of $27,541 \mathrm{MW}$. The contribution of DR to towards meeting the load during peak hours improved from $5.3 \%$ to $5.75 .3 \%$ in 2016 [22]. The results obtained indicated that the implementation of DSM proved to be an efficient method in meeting peak load demand without compromising the network stability. The authors in [23] proposed a probabilistic modelling approach that utilizes the available DR during emergencies to reduce ageing of the network's overhead lines and enhance its reliability. In [24], authors proposed interruptible load and capacity market DSM using the Iranian peak load curve as a case study. The results obtained helped the independent system operator (ISO) to distinguish and utilize related DR program which enhances the attributes of the load curve. Related works that attempt to simulate customers' behaviour to different DR programs in a real power network were done. In some of those works, authors investigated the reliability effects of DR programs and reliability indices for generation companies, and transmission network [25]. In [26], the authors proposed a multi-stage residential demand response (RDR) program for the South African system. The RDR was able to contribute to a significant reduction in the energy demand of the peak period.

In this research study, the implementation of DSM and integration of RE into the Freetown distribution network in Sierra Leone to meet the increasing load without compromising the network stability is presented. This research work was carried out in two stages: in phase I, interruptible or curtailable load DR is implemented using price elasticity concept to meet the peak load demand and improving the load profile in the capital (Freetown). In phase II, an introduction of hybridized RE technologies to supply the new load curve after implementation of DR is analyzed through simulation. A genetic algorithm (GA) was used for the optimal sizing of the hybridized renewable energy injection into the generation mix with the decrease in operational and maintenance cost as the objective function, alongside greenhouse gas abatement. The overall importance of this research is to help in providing economic and technical insights to policymakers for the implementation of DSM programs and integration of hybrid RE technologies into the generation mix in the Sierra Leonean capital, city of Freetown. 


\section{Methodology}

\subsection{Phase I: Demand Response}

The annual drop in the water level at the main Bumbuna Hydro dam which supplies electricity to the capital and some parts of the northern region of the country has forced grid operators and IPP's to issue notices for emergency load shedding and voluntary conservation [27]. This situation is as a result of varying climatic conditions, and the emergency load shedding is usually done within the capital city Freetown for large scale industrial consumers, i.e., MDI and residential consumers in response to the reduction in generation capacity. Insufficient generation capacity results in massive load shedding and constitutes a substantial financial loss to the distribution authority during the dry season. This problem can be mitigated by incorporating the DR mechanism already implemented by other countries reported in the literature. In literature [28], the International Energy Agency (IEA) referred to DSM as "changes that originate from the demand side of the market to achieve large scale energy efficiency improvements by deployment and use of improved technologies and changes in end-user behaviour or energy practices". Also, the 2008-2012 strategic plan was directed towards load-curve modification, and that of 2014-2018 centred on the planning needed to target the investment potential and adequate business models for beneficial market adaptation. These two segments are required for adequate and effective results.

DR can be described as the incentive payments that encourage a temporary reduction in electricity usage in response to a market pricing condition or when system reliability is compromised [29], and it can be grouped in two categories according to their operational mechanism, namely incentive-based and time-based demand response programs. Each of these categories is sub-divided into different programs as shown in Figure 1 below. Time-based rate programs are intended to alter patterns of electricity utilization, including the timing and level of electricity demand. Time-based rate programs include real-time pricing, critical peak pricing, critical peak rebate, variable peak pricing, and time-of-use rates administered through a tariff. Incentive-based demand response programs include direct load control, interruptible, demand bidding/buyback, emergency demand response, capacity market, and ancillary service market programs. Additional details on demand response can be found in [30]. However, this research will centre on introducing interruptible or curtailable load-based DR programs in the Freetown load curve.

\subsubsection{Overview of Interruptible Load Model}

Customers that sign up to this tariff are subject to curtailment or interruption to reduce utilization to a pre-indicated amount. The curtailed amount of power is based on system reliability constraints in return for an incentive payment or other forms of remuneration in the short term when system stability is being jeopardized due to excessive loading. Some industrial customers can shift or reschedule their demand in the wake of being informed by the utility [16,31]. If customers fail to comply with the contractual provisions, they will be penalized. In this research, the DR programs are generally only available for MDI customers from $12 \mathrm{~kW}$ up to $2 \mathrm{MW}$. It is expected that customers that sign up for this program readjust their demand within $35 \mathrm{~min}$ of notification by the utility via the advanced smart metering system. The efficient deployment of this program depends significantly on the infiltration level recorded on the installed smart meters. The frequency of interruptions is usually set based on a strict agreement between the utility and the customers, and it is usually restricted to not more than $100 \mathrm{~h}$ per year. 


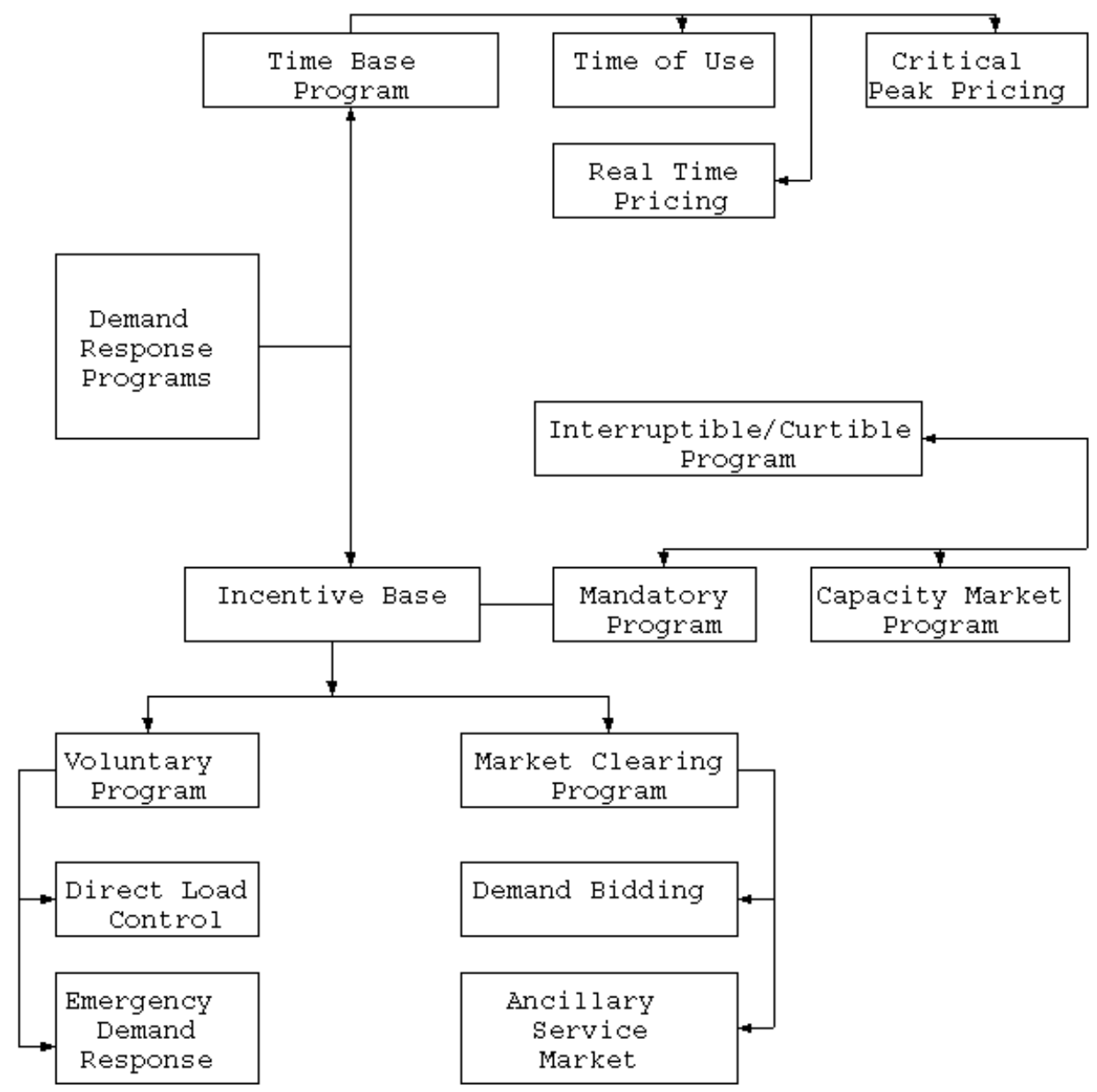

Figure 1. Demand response program categories.

\subsubsection{Mathematical Modelling of Interruptible Load DR}

In this work, the interruptible DR load model, the impact on the electricity demand prices, the imposed penalties, and the corresponding customer benefits on the Freetown load curve are described as follows:

The typical demand curve in Figure 2 demonstrates that the demand reduces as the price of the commodity rises, i.e., in most cases the rate of utilization of electricity was sensitive to price, which implies that a decrease in electricity price will increase the demand; hence, consumers will be encouraged to raise their demand when the price decreases [24].

$$
E=\left(\frac{\partial l}{l} / \frac{\partial p}{p}\right)
$$

where, $E$ is the elasticity coefficient, $p=$ electricity price and $l=$ load demand.

Customarily, a change in the price of one commodity will have impacts on the demand. For example, an increase in the price of electricity in the period $i$ will reduce the demand but may increase the demand in period $j$ if the price of electricity reduces. Negative "self-elasticity" is used to model the first effect, while a positive "cross-elasticity" can be used to model the second case [16];

$$
\begin{aligned}
& E_{i i}=\left(\frac{\partial l}{l} / \frac{\partial p}{p}\right) \leq 0 \\
& E_{i j}=\left(\frac{\partial l}{l} / \frac{\partial p}{p}\right) \geq 0
\end{aligned}
$$


where $E_{i i}$ is the self-elasticity coefficient, $E_{i j}$ is the cross-elasticity coefficient.

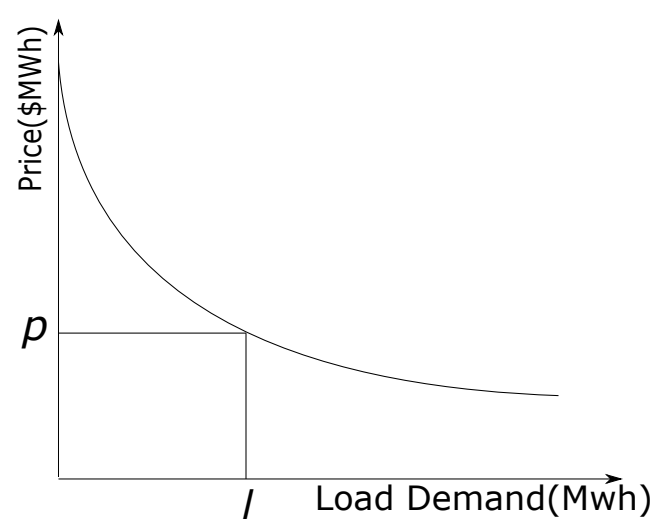

Figure 2. Demand curve.

Proposed Modelling of Single and Multi-period Elastic load

The incentive reward, customer benefits, and penalty are essential motivating factors for the customers to curtail or adjust their initial utilization $l_{0 i}$ value to the modified demand $l_{i}$ at period $i$, based on the contractual agreement with the utility provider.

$$
\triangle l_{i}=l_{i}-l_{0 i}
$$

Hourly incentive revenue for customers participating in this demand response program during the period $i$ is as shown in the equation below.

$$
\operatorname{IR}\left(\triangle l_{i}\right)=I N C_{i} \cdot\left(l_{i}-l_{0 i}\right),
$$

where $I R\left(\triangle l_{i}\right)$ is the incentive revenue payment for load reduction (\$) and INC is the incentive rate $(\$ / \mathrm{kWh})$.

In a situation whereby the participating customer fails to oblige to the condition of the contract agreement, the customer has to make the levied penalty payments.

$$
X_{p}\left(\triangle l_{i}\right)=Z_{i} \cdot\left(P i-\left[l_{i}-l_{0 i}\right]\right),
$$

where $X_{p}$ is the levied customer penalty charge $(\$), Z_{i}$ is the penalty rate $(\$ / k W h)$ and $P(i)$ is DR program level of contract agreement $(\mathrm{kWh})$ during the same period $i$. In this regard, the customer benefit, $Y$ for period $i$ is as shown below.

$$
Y=B\left(l_{i}\right)-l\left({ }_{i}\right) \cdot p(i)+I R\left(\triangle l\left({ }_{i}\right)-X_{p}\left(\triangle l\left({ }_{i}\right)\right)\right.
$$

where $B\left(l_{i}\right)$ and $p(i)$ are the customer income $(\$)$, and electricity price $(\$ / k W h)$ in $i$ period respectively. Assuming the consumers choose demand level $l_{i}$ in other to maximize their benefits after the demand response program then, $\frac{\partial Y}{\partial l_{i}}=0$ is equated to zero to maximize the consumer benefit.

$$
\frac{\partial Y}{\partial l_{i}}=\frac{\partial B\left(l_{i}\right)}{\partial l_{i}}-\rho_{o}(i)+\frac{\partial I R}{\partial l_{i}}-\frac{\partial X_{p}}{\partial l_{i}}=0 .
$$

So,

$$
\frac{\partial B\left(l_{i}\right)}{\partial l_{i}}=p(i)+I N C_{i}+Z_{i}
$$


The benefit function is a quadratic function as follows;

$$
B(l i)=B_{0}(i)+\rho_{o}(i)\left[l_{i}-l_{0 i}\right]\left\{1+\frac{l_{i}-l_{0 i}}{2 E_{i} \cdot l_{0 i}}\right\},
$$

where $B_{0}(i)$ and $\rho_{o}(i)$ are the benefit and electricity prices at nominal values respectively. Differentiating Equation (9) and solving for $\frac{\partial B}{\partial l_{i}}$ then substitute into Equation (8) yields;

$$
\rho(i)+I N C_{i}+Z_{i}=\rho_{o}(i)(i)\left\{1+\frac{l_{i}-l_{0 i}}{E_{i} \cdot l_{0 i}}\right\} .
$$

Customer utilization will be as shown in the following;

$$
l_{i}=l_{0 i}\left\{1+E_{i i} \cdot \frac{\rho(i)-\rho_{o}(i)+I N C_{i}+Z_{i}}{\rho_{o}(i)}\right\} .
$$

In the above equation, $l_{i}$ and $l_{0 i}$ will remain the same if the electricity price does prevail and remain the same without considering the value of the incentive and penalty after implementation of the DR program.

\section{Modelling of Multi-Period of the Interruptible Load Program}

In the multi-period, the cross elasticity $E_{i j}$ is calculated for the $i$-th period with respect to all other periods using the linearity premise given below;

$$
\frac{\partial l_{i}}{\partial p_{j}}: \text { constant for } \mathrm{i}, \mathrm{j}=1,2,3,4 \ldots . .24 \text {. }
$$

The linear relationship between price and demand

$$
l_{i}=l_{0 i}+\sum_{\substack{i=1 \\ i \neq j}}^{24} E_{i j} \cdot \frac{l_{0 i}}{\rho_{o}(j)} \cdot\left\{\rho(j)-\rho_{o}(j)\right\} \text { constant for } \mathrm{i}, \mathrm{j}=1,2,3,4 \ldots . .24 .
$$

It follows that the multi-period comprising incentive and penalty model can be express as shown below;

$$
l_{i}=l_{0 i}\left\{1+\sum_{\substack{i=1 \\ i \neq j}}^{24} E_{i j} \frac{\left[\rho(j)-\rho_{o}(j)+I N C_{j}+Z_{j}\right]}{\rho_{o}(j)}\right\}
$$

Combining Equations (11) and (14) will result in the economic model and the responsive model shown below;

$$
l_{i}=l_{0 i}\left\{1+E_{i i} \cdot \frac{\rho(i)-\rho_{o}(i)+I N C_{i}+Z_{i}}{\rho_{o}(i)}+\sum_{\substack{i=1 \\ i \neq j}}^{24} E_{i j} \frac{\left[\rho(j)-\rho_{o}(j)+I N C_{j}+Z_{j}\right]}{\rho_{o}(j)}\right\} .
$$

Equation (15) shows the customer benefit in the $24 \mathrm{~h}$ interval when signed up to this program. 


\subsection{Phase II: Power System Formulation Introduction of Renewable Energy into Demand Response Program}

RE technologies, such as solar power and BESS are increasingly becoming an alternative energy source due to their zero emission of greenhouse gases, energy security, availability, etc. PV-panels convert solar irradiance into electrical power; the installation can be standalone or grid-connected. Due to the intermittent nature of solar radiation, the PV is usually connected with a BESS system to offset the intermittent nature of the solar power, i.e., hybrid connection of PV and BESS. The authors in [32] presented hybridized RE source-thermal generation model was presented for the Northern Cyprus Turkish Republic. The study suggests an enhancement in a hybrid RE-thermal power system execution by predicting reliable outputs that can fuse RE technologies to the conventional power source.

In this research, the DSM approach is employed when the existing diesel generating units in the network cannot meet the required load demand, after the interruptible or shifting DR program has been executed and the RE technology has been introduced. Energy from the solar generators or grid power may be stored when there is excess generated PV power or when the cost of electricity from the grid is economical. The stored energy can be controlled for economical usage in future when the electricity demand is high during load peak times, or when there is unavailable PV power. It is worthy to note that RE sources are being utilized in the valley and low peak periods. Figure 3 shows the system configuration and the flowchart, of the complete design process of two-stage DR program using RE sources, are presented in Figure 4 below.

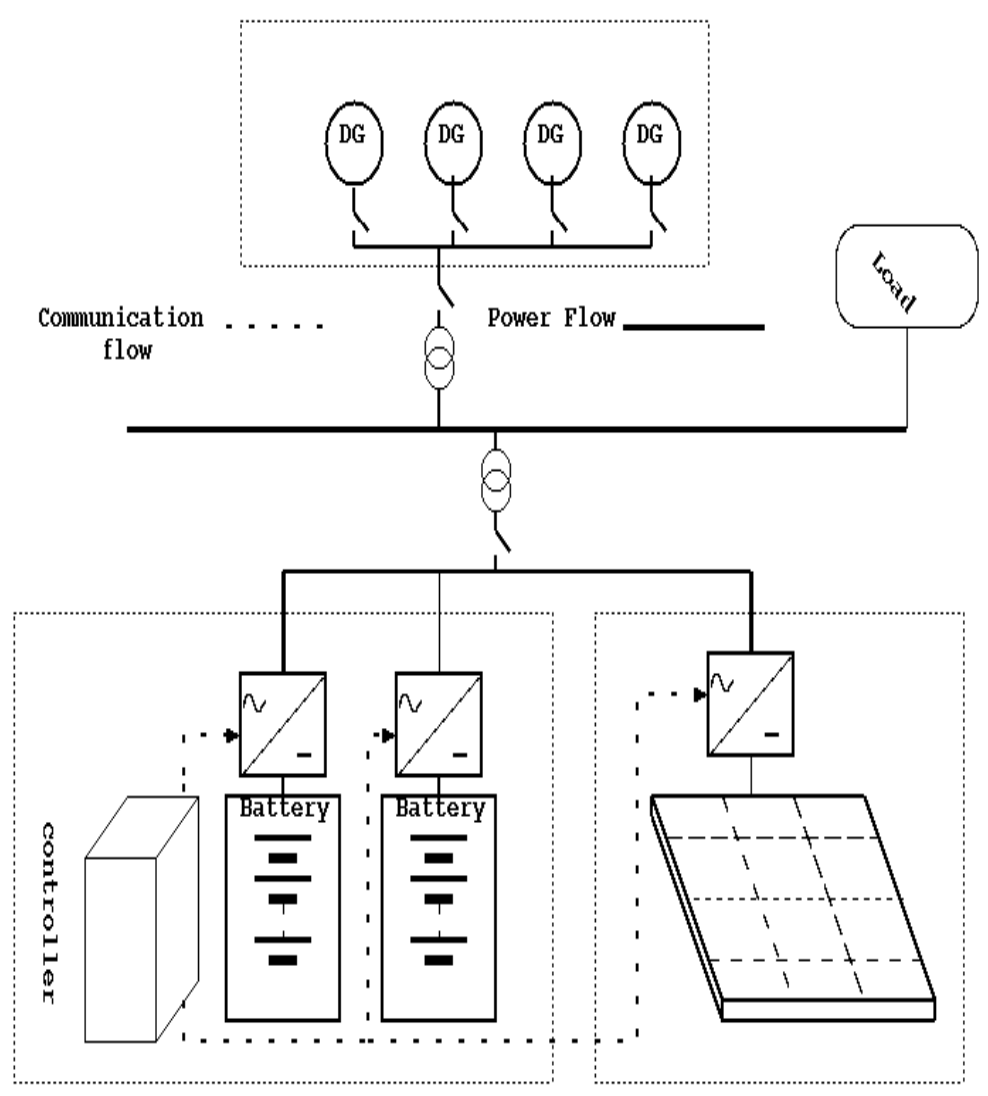

Figure 3. The proposed system model. 


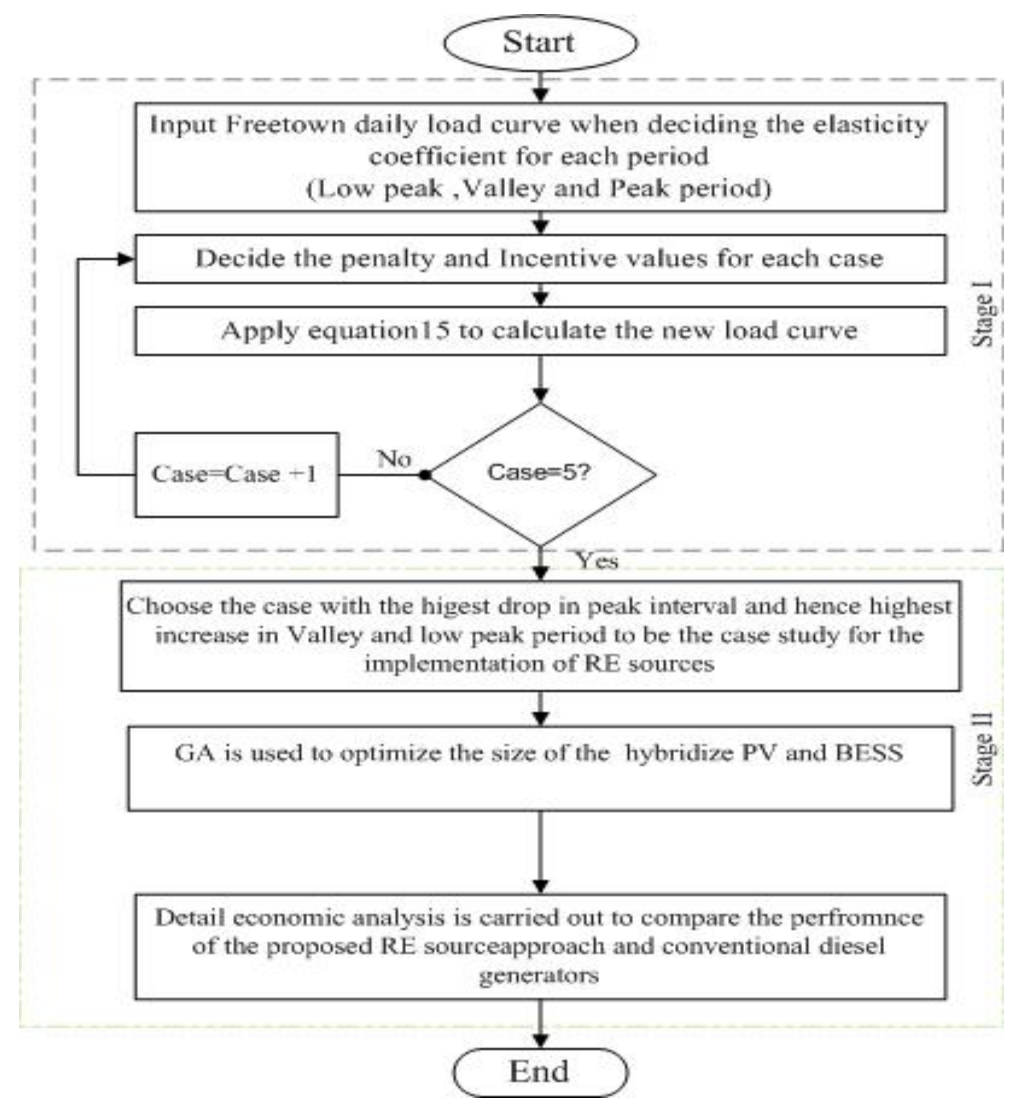

Figure 4. Flowchart of the proposed model.

The parameters used in the system formulation are given in Table 1.

Table 1. Variables used in this research.

\begin{tabular}{ccc}
\hline VARIABLE & NOMENCLATURE & VALUE \\
\hline Interest rate & $\mathrm{i}$ & 0.1 \\
Index year & $\mathrm{e}(\mathrm{years})$ & \\
Inflation rate & $\sigma$ & 0.04 \\
Escalation rate & $\mu_{p v}=\mu_{B a t}$ & 0.075 \\
Inverter efficiency & $\eta_{i n v}$ & 0.9 \\
PV Initial cost & $\tau_{P V}\left(\$ / \mathrm{m}^{2}\right)$ & 251 \\
Total Area of PV & $X_{p v}\left(\mathrm{~m}^{2}\right)$ & \\
Annual O\&M Cost of PV & $O M_{p v}\left(\$ / \mathrm{m}^{2} / \mathrm{yr}\right)$ & $0.01 \times X_{p v}$ \\
The replacement cost of PV & $R_{c p v}(\$)$ & 0 \\
Resale price of PV & $S_{r p v}$ & $0.25 \times \tau_{P V}$ \\
PV efficiency & $\eta_{p v}$ & 0.14 \\
The capital Investment cost of PV & $V_{p v}(\$)$ & \\
Battery charging efficiency & $\eta_{b a t}$ & 0.9 \\
Battery discharging efficiency & $\eta_{d i s}$ & 0.9 \\
Number of Batteries & $Z_{b a t}$ & \\
Battery cost & $Q_{b a t}(\$ / \mathrm{MW})$ & 200,000 \\
Battery replacement cost & $R_{c b a t}(\$)$ & \\
Hourly self discharge & $\gamma$ & 0 \\
Battery Capacity & & $50 \mathrm{~kW}$ \\
\hline
\end{tabular}




\subsubsection{The Output of PV Array}

The output power supplied by the PV panel during the period $i$ in the valley and low peak period is presented in the equation below;

$$
P V_{\text {out }}=\eta_{P V} \cdot X_{P V} \cdot H(i)
$$

where $P V_{\text {out }}$ is the PV output power, $\eta_{P V}$ efficiency of the PV panels, $X_{P V}$ is the total area occupied by the panels in $\mathrm{m}^{2}$ and $H(i)$ is the solar radiation in period $i$ in $\mathrm{kW} / \mathrm{m}^{2}$.

\subsubsection{Battery Energy Storage System(Bess)}

The aggregated power from the thermal unit $P_{\text {th }}$ and PV panel in period $i$ is as shown below;

$$
P_{T}(i)=P_{p v}(i)+P_{t h}(i)
$$

where $P_{T}$ is the sum of the generated power.

From Equation (17) above, if the total generated power cannot meet the load demand $l$ at any period $i$, it indicates that the state of charge (SoC) of the battery at the period $i$ with inverter efficiency $\eta_{i n v}$ is:

$$
P_{T}(i) \geq \frac{l(i)}{\eta_{\text {inv }}}
$$

At any given period $i$ when there is an excess generation from the thermal and PV, BESS can be charged. The state of charge can be calculated as shown below [33];

$$
\operatorname{SoC}(i)=\operatorname{SoC}(i-1) \cdot(1-\gamma)+\left(P_{T}(i)-\frac{l(i)}{\eta_{\text {inv }}}\right) \eta_{\text {bat }}
$$

The storage state of charge, $\operatorname{SoCs}(i)$, at the end of the period $i$, as a function of its state of charge at the previous period of the charging or discharging that took place during the period $i$.

Where $\operatorname{SoC}(i)$ is the state of charge, $\gamma$ is the self-hourly discharge rate and $\eta_{\text {bat }}$ battery charging efficiency.

$$
\text { SoC }(i) \leq S_{o} C^{\max },
$$

where $S o C_{\max }$ is $80 \%$ of the total capacity of the battery bank. In cases wherein $P_{T}(i) \leq \frac{l(i)}{\eta_{\text {inv }}}$, then there is insufficient generation capacity from i.e., PV and thermal, the load demand will be met by the battery energy storage system. During the discharging period, the $\mathrm{SoC}$ is as follows;

$$
\operatorname{SOC}(i)=\operatorname{SOC}(i-1) \cdot(1-\gamma)+\frac{\left(\frac{l(i)}{\eta_{\text {inv }}}-P_{T}\right)}{\eta_{\text {dis }}},
$$

where $\eta_{\text {dis }}$ is the efficiency of discharge of the battery

The state of charge should not be less the minimum $S_{o} C_{\text {min }}$

$$
\operatorname{SoC}(i) \geq \operatorname{SoC}_{\min } \text {. }
$$

Therefore the minimum state of charge is $20 \%$ of the total capacity of the battery bank.

\section{Case Study and Results of the Simulation}

In order to evaluate the effect of interruptible or curtailable DR, the proposed approach is employed to Freetown network load demand using December 2017 data, as shown in Figure 5. The average electricity price negotiated by EGTC, EDSA and the Ministry of Energy (MoE) in 2017 was $0.178 \$ / \mathrm{kWh},[34,35]$. The daily load curve is divided depending on the nature of demand into three intervals: Low peak (00:00-7:00), valley (8:00-14:00) and peak load (15:00-22:00); and DR program will 
be employed to decrease the demand in peak load periods. Data was acquired through desk research, key informant interviews, sector policymakers and discussions with senior engineers at EDSA and EGTC. In this research, implementation of this program is $10 \%$ modification of the total load of the participating customers and its incumbent for customers who signed up to this program to shed $10 \%$ of their load when being notified as in the agreed contract. The incentive and penalty values designated for customers who signed up for this program and the price elasticity values are shown in Tables 2 and 3 respectively [36].

Table 2. Incentives and penalties values.

\begin{tabular}{ccc}
\hline CASE & INCENTIVE \$/kWh & PENALTY $\mathbf{~ / k W h ~}$ \\
\hline 1 & 0 & 0 \\
2 & 0.178 & 0 \\
3 & 0.089 & 0.089 \\
4 & 0.029 & 0.059 \\
5 & 0.178 & 0.178 \\
\hline
\end{tabular}

Table 3. Self and cross elasticity for various periods.

\begin{tabular}{cccc}
\hline Period & Low Peak (00:00-7:00) & Valley (8:00-14:00) & Peak Load (15:00-22:00) \\
\hline Low Peak (00:00-7:00) & -0.1 & 0.01 & 0.012 \\
Valley (8:00-14:00) & 0.01 & -0.1 & 0.016 \\
Peak Load (15:00-22:00) & 0.012 & 0.016 & -0.1 \\
\hline
\end{tabular}

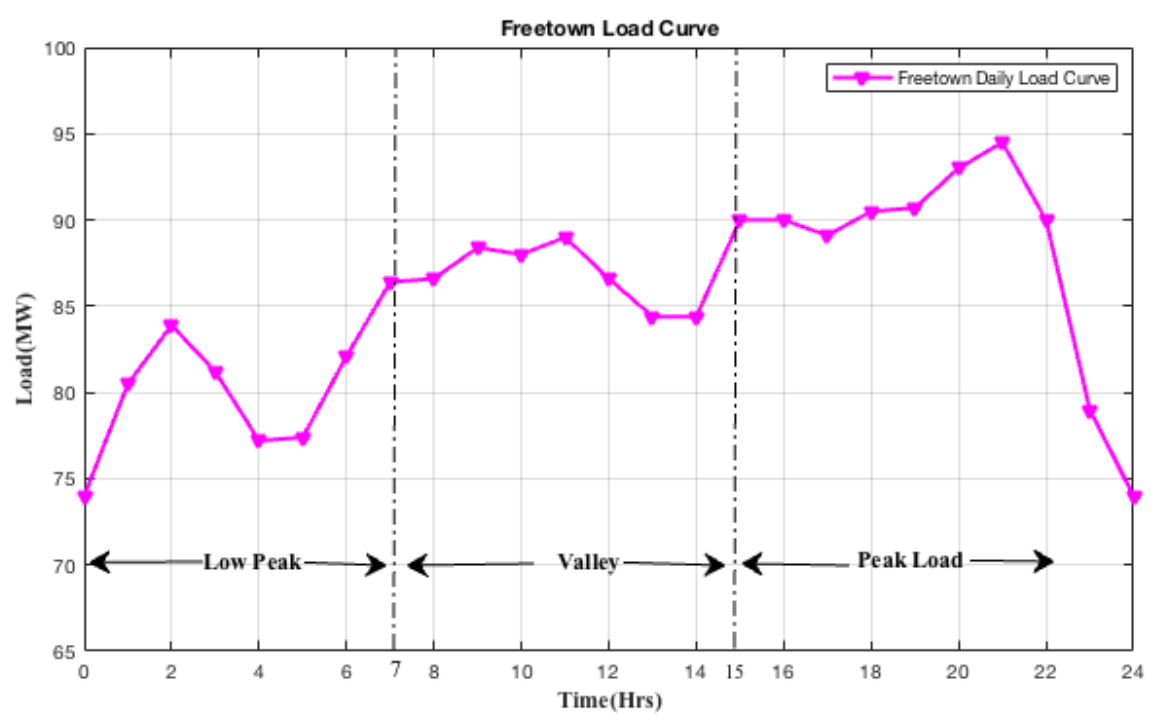

Figure 5. Freetown demand curve.

\subsection{Results of Dr Program Execution and Analysis (Phase I)}

1. Case 1 In case I, the peak load curve was considered without the execution of the proposed DR program. As shown in Table 4, the peak load was 94.5 MW, energy consumption was $2057 \mathrm{MWh}$, customer bill was $\$ 366,130$, peak to valley distance was $21 \mathrm{MW}$. These four indices improved after implementation of the proposed DR model, as subsequently explained in the following subsections.

2. Case 2 As shown in Table 4, penalty and incentives are taken as $0.178 \$ / \mathrm{kWh}$ and $0 \$ / \mathrm{kWh}$ respectively. Comparing the results with the base case, net reductions were observed on the following; peak load, by $4.3 \%$ (90.42 MW), energy consumption by $2.2 \%$ (2012 MWh), customer bill by $(2.2 \%) \$ 35,160$ and peak to valley reduction by $23.8 \%$ (16 MW) as shown in Figure 6. Also, 
the customer benefit increased to $\$ 18,813$ and supplier benefits reduced by $5.1 \%(\$ 18,820)$ as compared to the base case.

3. Case 3 In this case, the incentive and penalty are both at the equivalent value of $0.089 \$ / \mathrm{kWh}$ as observed in Figure 6 which also depicts similar profile characteristic as in case 2 with decrease customers bill by $2.18 \%$ (\$7970), 4.12\% (90.42 MW) of peak load reduction. Also, supplier revenue decreased by $3.13 \%$ ( $\$ 11470)$ as compared to the base case scenario. The incentive payment in case 2 doubled as in case 3, which is legitimized by Equation (15).

4. Case 4 From Table 4 , taking penalty and incentives as $0.029 \$ / \mathrm{kWh}$ and $0.059 \$ / \mathrm{kWh}$ respectively and comparing the results obtained to that of the case 1, it can be observed that there is net reduction in the following: peak load by 3.5\%(91 MW), energy consumption by $1.06 \%$ (2035 MWh), and customer bill by $1.1 \%(\$ 362,190)$ and peak to valley reduction by $19 \%(17 \mathrm{MW})$ as shown in Figure 6 .

5. Case $5 \mathrm{In}$ this case, given the incentive and penalty values as $0.0178 \$ / \mathrm{kWh}$. From the simulation and comparing with the results obtained in case I, it observed that there is a net reduction in energy consumption by $4.35 \%(1967.40 \mathrm{MWh})$, customer bill by $4.32 \%(\$ 350,200)$ and peak load by $2.80 \%(91.85 \mathrm{MW})$ as shown in Figure 6. Also, an increase in supplier revenue, customer benefit was observed from the simulation as shown in Table 4.

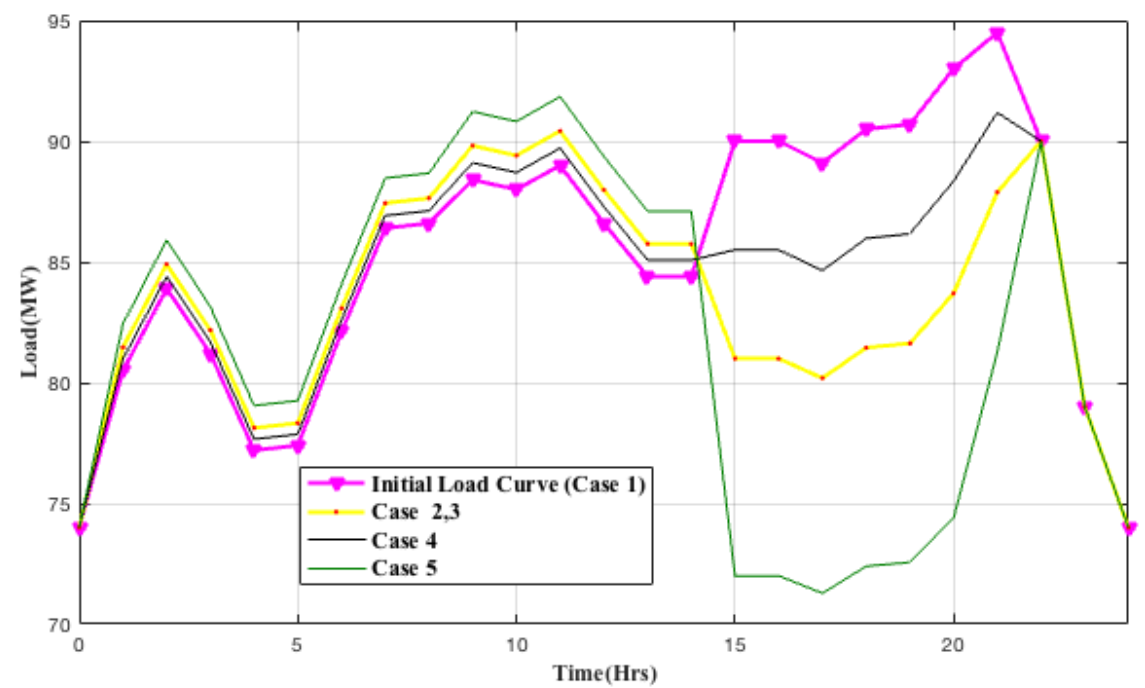

Figure 6. Impact of demand response for different scenarios.

Table 4. Analysis and load profile characteristics.

\begin{tabular}{|c|c|c|c|c|c|}
\hline & CASE-1 (Base) & CASE-2 & CASE-3 & CASE-4 & CASE-5 \\
\hline Customer Bill (\$) & $366,130.00$ & $358,160.00$ & $358,160.00$ & $362,190.00$ & $350,200.00$ \\
\hline Peak Load (MW) & 94.50 & 90.42 & 90.42 & 91.22 & 91.85 \\
\hline Load Factor (\%) & 90.69 & 92.72 & 92.72 & 92.93 & 89.25 \\
\hline Customer Benefit (\$) & 0.00 & $18,813.00$ & $13,137.00$ & 3826.30 & $37,627.00$ \\
\hline Supplier Revenue (\$) & $366,130.00$ & $347,310.00$ & $354,660.00$ & $364,370.00$ & $332,090.00$ \\
\hline Energy reduction $(\%)$ & 0 & 2.22 & 2.22 & 1.09 & 4.55 \\
\hline Peak Reduction (\%) & 0 & 4.31 & 4.31 & 3.46 & 2.81 \\
\hline Peak to Valley (MW) & 20.50 & 16.42 & 16.42 & 17.23 & 20.57 \\
\hline
\end{tabular}

\subsection{Results of the Introduction of Renewable Energy (Phase II)}

Figure 7 shows the introduction of RE technologies into the generation mix after the execution of the demand response program. The proposed model is evaluated using a genetic algorithm (GA). GA is a method to solve both constrained and unconstrained optimization problems that are based on natural 
selection. A key step in GA applications is the definition of the objective (fitness) function which is the function to optimize. In this case, the fitness functions are the summation of the net mismatch between the generation and the load, i.e., for low peak, Valley, and peak load hours. The fitness function $\left(F_{x}\right)$ is shown in equation (23). The obtained best fitness is as presented in Figure 8

$$
F_{x}=\sum_{i=1}^{N} \mid\{\text { gen }- \text { load }\} \mid
$$

In this research, PV and BESS are considered to offset the deficiency in the existing generation capacity from the thermal units in peak and valley periods, especially during the dry season, when the main hydro supplying electricity to the Capital, is reduced to more than half of its designed capacity. Table 5 shows the solar irradiance [37]. Case 5 was selected for the penetration of PV and BESS due to the highest drop in peak period henceforth highest increase in the valley and low peak period occurred in this case. It represents the largest gap and should be filled in valley and peak interval and from the simulation results shown in Figure 7, it is observed that, between the hours 00:00-10:00 h, where we have limited solar radiation, the battery can be seen discharging it stored energy covering the shortfall for the PV power. From 11:00-17:00 h, we observed an increase in solar irradiance. During this period the PV will be providing power supply while the battery is charging. The state of charge and discharge is as shown in Figure 7.

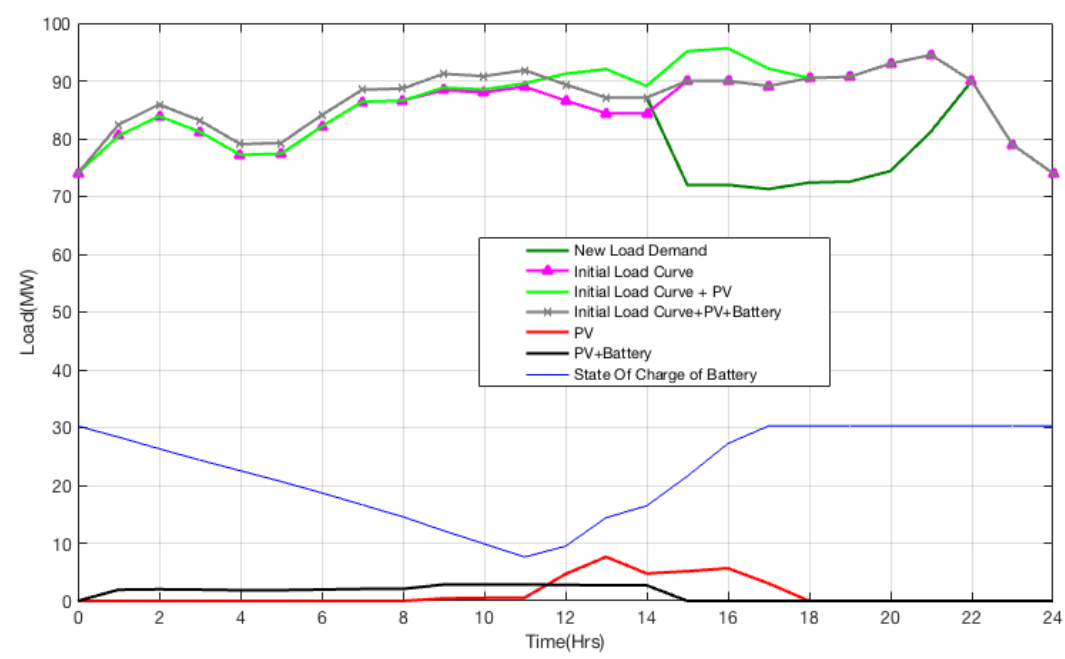

Figure 7. Introduction of renewable energy.

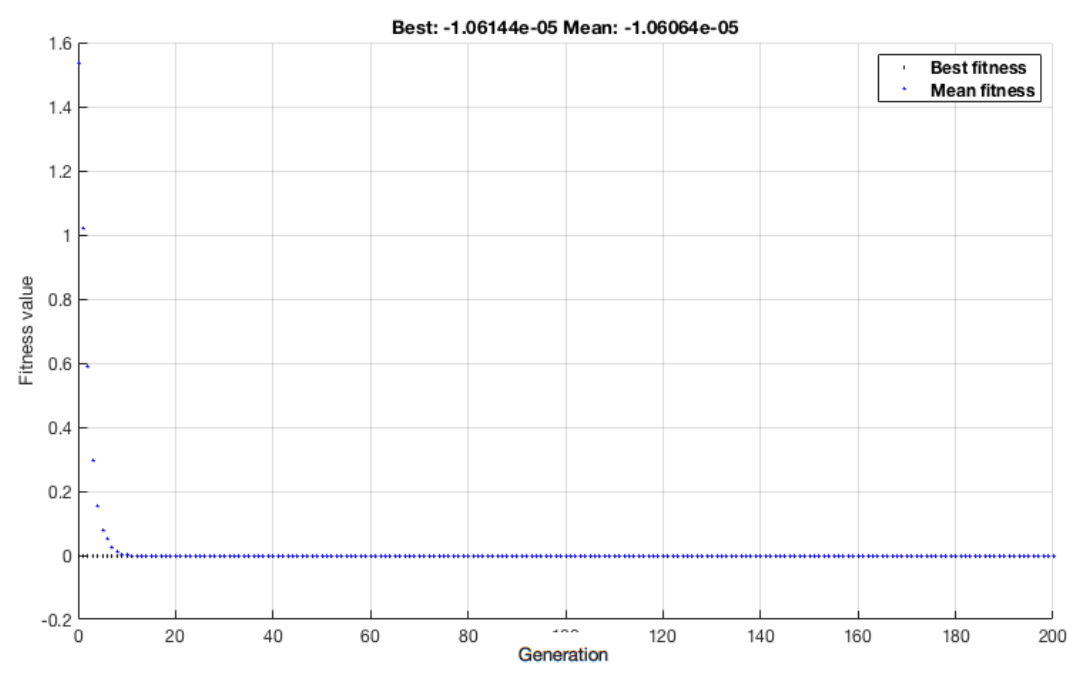

Figure 8. Fitness function. 
Table 5. Solar irradiance.

\begin{tabular}{cccc}
\hline Time & Solar Radiation $\mathbf{w} / \mathbf{m}^{2}$ & Time & Solar Radiation $\mathbf{w} / \mathbf{m}^{2}$ \\
\hline 0:00 & 0 & $12: 00$ & 531 \\
1:00 & 0 & $13: 00$ & 873 \\
2:00 & 0 & $14: 00$ & 543 \\
$3: 00$ & 0 & $15: 00$ & 587 \\
$4: 00$ & 0 & $16: 00$ & 646 \\
$5: 00$ & 0 & $17: 00$ & 347 \\
$6: 00$ & 0 & $18: 00$ & 0 \\
$7: 00$ & 0 & $19: 00$ & 0 \\
$8: 00$ & 0 & $20: 00$ & 0 \\
$9: 00$ & 50 & $21: 00$ & 0 \\
10:00 & 60 & $22: 00$ & 0 \\
11:00 & 66 & $23: 00$ & 0 \\
\hline
\end{tabular}

In order to investigate the robustness and effectiveness of the proposed control scheme from the economic point of view, the annual cost of implementing RE projects are compared with the conventional diesel generators suppliers.

\subsubsection{Cost Analysis}

The cost analysis is used to measure the economic performance of the deployed DR program considered for the system under study. For a project life of 20 years, the main costs considered were the capital cost of investment, cost of operation, maintenance cost and resale cost of salvageable components. The battery was replaceable after every five years throughout the project life, and this was considered in the cost analysis.

1. PV system cost The capital investment cost over 20 years period of operation is as shown below, and parameters used in the cost analysis are given in Table 1;

$$
V_{p v}=\tau_{P V} \times X_{p v},
$$

where $\tau_{P V}, X_{p v}$ are the initial investment cost and the total area of the PV respectively. The total operational and maintenance cost $\left(O M_{c p v}\right)$ of $\mathrm{PV}$ is as shown below, where $\mu_{p v}$ denotes the escalation rate for 20 years operational period.

$$
\begin{gathered}
O M_{p v}=\tau_{p v} \times X_{p v} \times\left[\left(\frac{1+\mu_{p v}}{1+i}\right)^{e}\right] \\
O M_{c p v}=\sum_{e=1}^{20}\left(O M_{p v}\right) .
\end{gathered}
$$

The PV replacement $\left(R_{c p v}\right)$ cost is considered zero, therefore the total resale price after the 20 years period is as shown;

$$
S_{r p v}=s_{p v} \times X_{p v} \times\left[\left(\frac{1+\sigma_{p v}}{1+i}\right)^{20}\right]
$$

It follows that the total cost of PV $X_{n}$ over 20 years is

$$
X_{n}=V_{p v+O M_{C P V}-S_{r p v}} .
$$


2. Battery cost In this research, the project lifetime was 20 years and the lifetime of the battery was five years, it follows that the battery should be replaced three times during the project life cycle. The capital investment cost of the battery for five years is as shown below;

$$
\text { Batt }_{c}=Z_{b a t} \times Q_{b a t}
$$

Replacement cost after period $j$ is given by

$$
R_{c b a t}=Z_{b a t} \times Q_{b a t} \times\left[\left(\frac{1+\mu_{B a t}}{1+i}\right)^{e}\right] .
$$

Total replacement for 20 years period

$$
R_{c b a t}=Z_{b a t} \times Q_{b a t} \times \sum_{e=5,10,15}\left[\left(\frac{1+\mu_{B a t}}{1+i}\right)^{e}\right] .
$$

For diesel generators, the maintenance cost of $0.0075 \$ \mathrm{kWh}$ is considered [38]. Moreover, depending on the Freetown load curve, diesel generators will operate approximately $14 \mathrm{~h}$ daily in this scheme (Valley to Off-Peak hours), that will give about $5110 \mathrm{~h}$ of annual operation. As the statistics recommend replacement of the diesel generator after overuse of 20,000 operating hours, the conventional generators are replaced after every four years, and 1.25 \$million/MW [38] is considered as the replacement cost. Figure 9 shown below validates the superiority of the proposed model of RE sources inclusion to cover all its life cycle cost only after 12 years from the lifetime of the proposed project and the remaining eight years will be considered profit for the supplier. Moreover, the environmental effects of conventional diesel generators will be decreased significantly by applying this approach, and this can be an additional gain for utilizing the proposed methodology.

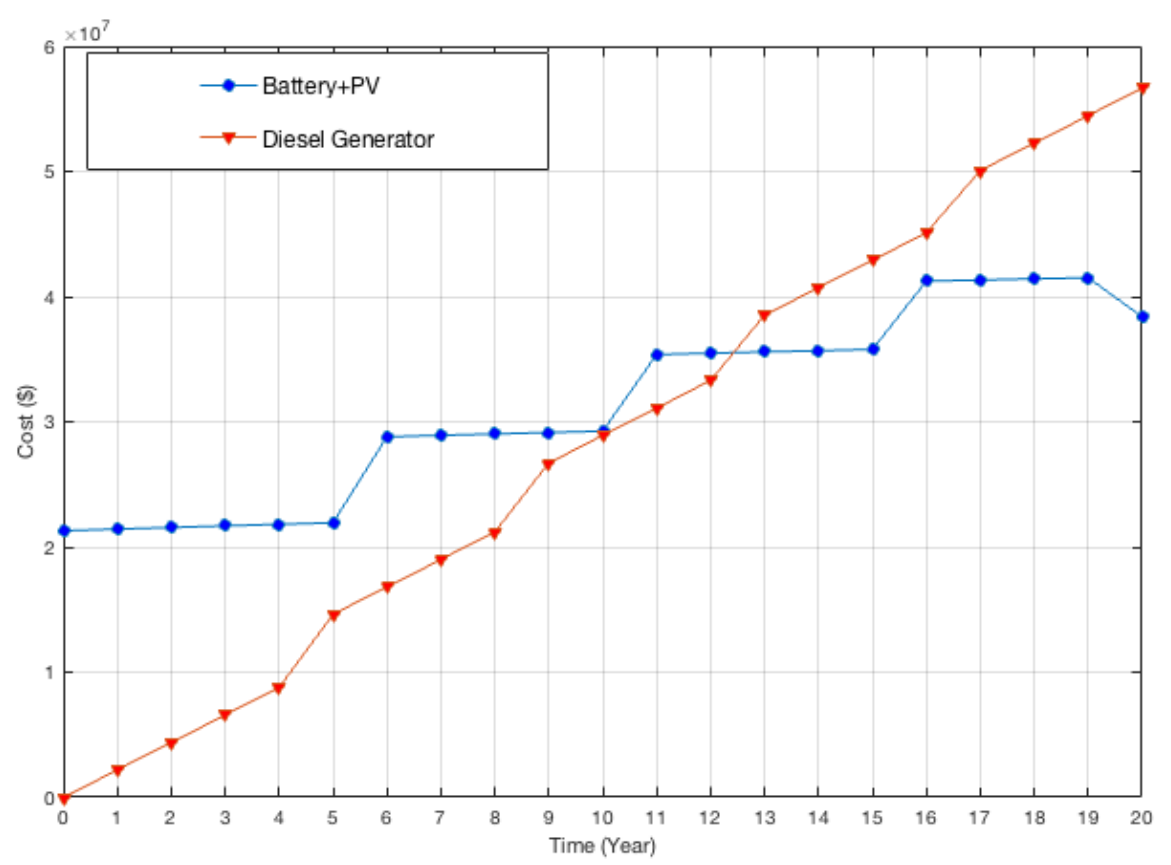

Figure 9. Cost comparison of renewable energy (RE) and diesel generators.

\section{Results Discussion}

In this research, formulation of DR program for the electric power system of Sierra Leone, considering Freetown (capital city) load curve was investigated. The research was divided into 
two implementation phases which mainly concentrated on the economic benefits of the consumers and suppliers.

- In phase I, the proposed control scheme was applied to the Freetown distribution network. Five case studies were considered with different incentive and penalty values. The results obtained from the simulation validate the efficiency of the proposed DR control approach to maximize customer profit by decreasing the customer bills and also increasing customer benefits. Furthermore, from the supplier point of view, the proposed methodology succeeded in decreasing the peak load, and reduced the energy consumption; in addition to mitigating the load factor that significantly enhances the power of the power system.

- In phase II; PV and BESS are introduced as RE-sources to meet the variance in load in the valley and Off-peak periods, hence, decreasing the use of conventional diesel generators. This step will lead to a decrease of GHG emissions which has harmful effects on the environment.

- The cost-benefit analysis was implemented to investigate and compare the economic effects of RE sources inclusion to that of convention diesel generators. The results confirm the ability of RE sources to cover the lifecycle cost of the project after twelve years. Depending on these results, the supplier can gain eight years of profit due to the RE energy sources inclusion in addition to its non-hazardous effect on the environment.

\section{Conclusions}

A novel two-stage DR program using RE sources has been executed in this paper. In the first stage, interruptible or curtailable DR program was employed with the daily load curve of Freetown, Sierra Leone's capital city, to shift the customer demand from the peak load periods to the valley and low peak periods. Additionally, the PV and BESS are utilized to meet the increasing demand in the valley and low peak periods after implementation of the DR program. The GA is used to optimize the size of PV and BESS. Five scenarios are implemented to confirm the effect and robustness of the proposed DR model to decrease peak load and increase load factor and customer benefits.

Moreover, a detailed cost analysis is held to investigate the superiority of the proposed RE inclusion approach to decrease the total cycle cost compared to that of diesel generators. The performance of the system is enhanced significantly by using the proposed two-stage control methodology. Simulation results show the ability of the proposed DR programs to decrease the customer bill, reduce peak load, mitigate load factor and also increase customer benefits. Furthermore, simulations clarify that RE sources inclusion approach will cover its lifecycle cost after 12 years from the total lifetime of the project, which means that at least eight years of profit for the supplier in addition to a significant reduction of environmental of conventional generators.

Author Contributions: A.C.: Conceptualization, Data curation, formal analysis, methodology, investigation, software, validation, writing the original draft, writing review and editing; M.E.L.: Formal analysis, methodology, software, validation writing review and editing. K.M.K.: Software and formal analysis; T.S.: Project administrator, supervision, validation and funding acquisition; P.M.: Writing original draft and validation; S.C.: Writing original draft and Validation.

Funding: This research received no external funding

Conflicts of Interest: The authors declare no conflict of interest.

\section{Nomenclature}

MDI maximum demand index

DR demand response

BESS battery energy storage

GHG green house gas

DSM demand side management

IEA international energy agency

NPA national power authority 
EDSA electricity distribution and supply authority

EGTC electricity generation and transmission company

AfDB Africa Development Bank

ISO independent system operator

RDR residential demand response

$E_{i, j} \quad$ cross elasticity

$E_{i, i} \quad$ self elasticity

$l_{o i} \quad$ initial load.

$l_{i} \quad$ modified demand

$i \quad i$-th period

$j \quad j$-th period

$I N C_{i} \quad$ incentive rate

$B_{o}(i) \quad$ benefit at nominal value

$Z_{i} \quad$ penalty rate

$\rho_{o}(i) \quad$ electricity price at nominal value

$\mathrm{Y} \quad$ customer benefit

PV_out output power of PV

GA genetic algorithm

IPP independent power producers

PV photovoltaic

RE renewable energy

EU European Union

E elasticity

$\rho(i) \quad$ electricity price

1 load demand

$P(i) \quad$ DR program contract

$B\left(l_{i}\right) \quad$ customer income in period $i$-th

$\operatorname{IR}\left(\triangle l_{i}\right) \quad$ Incentive revenue payment

$X_{p}\left(\triangle l_{i}\right) \quad$ levied customer penalty

$\eta_{p v} \quad$ the efficiency of PV panel

$X_{p v} \quad$ the area occupied by the PV-panel

$H_{i} \quad$ solar radiation

$P_{T} \quad$ Sum of aggregated power

$P_{P V}(i) \quad$ PV power in $i$-th period

$P_{t h} \quad$ aggregated power of thermal units

SoC state of charge of battery

$\eta_{\text {inv }} \quad$ inverter efficiency

$\gamma \quad$ hourly discharge rate

$\eta_{\text {bat }} \quad$ battery charging efficiency

$C_{\text {bat }} \quad$ nominal capacity of the battery bank

$\eta_{\text {dis }} \quad$ battery discharging efficiency

$\mathrm{SoC}_{\min }$ minimum state of charge of the battery

SoC $C^{\max }$ maximum state of charge of the battery

e index year

$V_{p v} \quad$ capital investment cost

$\tau_{p v} \quad$ initial investment cost of PV

$O M_{p v} \quad$ annual operational and maintenance cost of PV

$\mu_{p v} \quad$ escalation rate

$R_{c p v} \quad$ the replacement cost of PV

pv resale cost of PV

$\sigma_{p v} \quad$ the inflation rate of PV

$X_{n} \quad$ total cost of PV over 20 years

Batt $_{c} \quad$ capital cost of battery

$Z_{\text {bat }} \quad$ total number of battery

$Q_{n} \quad$ battery cost 
$R_{\text {cbat }}$ the replacement cost of battery

$\mu_{\text {bat }} \quad$ escalation rate of battery

\section{References}

1. The World Bank Global Tracking Framework 2017: Progress Toward Sustainable Energy. Available online: http:/ / www.worldbank.org (accessed on 1 March 2019).

2. Lee, J.T.; Callaway, D.S. The cost of reliability in decentralized solar power systems in sub-Saharan Africa. Nat. Energy 2018, 3, 960. [CrossRef]

3. Owusu, P.A.; Asumadu-Sarkodie, S. A review of renewable energy sources, sustainability issues and climate change mitigation. Cogent Eng. 2016, 3, 1167990. [CrossRef]

4. UNDP: National Energy Profile of Sierra Leone. Available online: http://www.sl.undp.org (accessed on 5 March 2019).

5. STATISTICS SIERRA LEONE: 2015 Population and Housing Census. Available online: https://www. statistics.sl (accessed on 5 March 2019).

6. Konneh, D.A.; Howlader, H.O.R.; Shigenobu, R.; Senjyu, T.; Chakraborty, S.; Krishna, N. A Multi-Criteria Decision Maker for Grid-Connected Hybrid Renewable Energy Systems Selection Using Multi-Objective Particle Swarm Optimization. Sustainability 2019, 11, 1188. [CrossRef]

7. EEG Energy Insight: Developing a Programme of Research on the Electricity Sector in Sierra Leone. Available online: https: / / assets.publishing.service.gov.uk (accessed on 17 August 2018).

8. The Ministry of Foreign Affairs: Sector Scan, The Energy Sector in Sierra Leone. Available online: https: / / www.rvo.nl (accessed on 5 March 2019).

9. The National Electricity ACT, 2011: Supplement of the Sierra Leone Gazette Vol.CXIII, No.6 Dated 9th February 2012. Available online: http:/ / www.sierra-leone.org (accessed on 5 March 2019).

10. Konneh, D.; Lotfy, M.; Shigenobu, R.; Senjyu, T. Optimal Sizing of Grid-connected Renewable Energy System in Freetown Sierra Leone. IFAC-PapersOnLine 2018, 51, 191-196. [CrossRef]

11. Adewuyi, O.B.; Lotfy, M.E.; Akinloye, B.O.; Howlader, H.O.R.; Senjyu, T.; Narayanan, K. Security-constrained optimal utility-scale solar PV investment planning for weak grids: Short reviews and techno-economic analysis. Appl. Energy 2019, 245, 16-30. [CrossRef]

12. Mohagheghi, S.; Yang, F.; Falahati, B. Impact of demand response on distribution system reliability. In Proceedings of the IEEE Power and Energy Society General Meeting, San Diego, CA, USA, 24-29 July 2011; pp. 1-7. [CrossRef]

13. Hasani Shoreh, M.; Siano, P.; Shafie-Khah, M.; Loia, V.; P.S. Catalão, J. A survey of industrial applications of Demand Response. Electr. Power Syst. Res. 2016, 141, 31-49. [CrossRef]

14. Behrangrad, M. A review of demand side management business models in the electricity market. Renew. Sustain. Energy Rev. 2015, 47, 270-283. [CrossRef]

15. Shigenobu, R.; Adewuyi, O.B.; Yona, A.; Senjyu, T. Demand response strategy management with active and reactive power incentive in the smart grid: A two-level optimization approach. AIMS Energy 2017, 5, 482-505. [CrossRef]

16. Kirschen, D.S.; Strbac, G.; Cumperayot, P.; de Paiva Mendes, D. Factoring the elasticity of demand in electricity prices. IEEE Trans. Power Syst. 2000, 15, 612-617. [CrossRef]

17. Torriti, J.; Hassan, M.; Leach, M. Demand response experience in Europe: Policies, programmes and implementation. Energy 2010, 35, 1575-1583. [CrossRef]

18. Alasseri, R.; Tripathi, A.; Joji Rao, T.; Sreekanth, K. A review on implementation strategies for demand side management (DSM) in Kuwait through incentive-based demand response programs. Renew. Sustain. Energy Rev. 2017, 77, 617-635. [CrossRef]

19. Ming, Z.; Song, X.; Mingjuan, M.; Lingyun, L.; Min, C.; Yuejin, W. Historical review of demand side management in China: Management content, operation mode, results assessment and relative incentives. Renew. Sustain. Energy Rev. 2013, 25, 470-482. [CrossRef]

20. Eskom's Energy Efficiency and DEMAND-side Management (EEDSM) Incentive Program. Available online: http:/ / iepd.iipnetwork.org (accessed on 7 March 2019). 
21. Lorek, S.; Trotta, G. Country Report Finland. An Inventory of Policies, Business and Civil Society Initiatives, Focusing on Heating, Hot Water and the Use of Electricity. EUFORIE-European Futures for Energy Efficiency; 2015. Available online: https://www.researchgate.net/publication/313240816_Country_Report_Finland_ An_inventory_of_policies_business_and_civil_society_initiatives_focusing_on_heating_hot_water_and_ the_use_of_electricity_EUFORIE_-_European_Futures_for_Energy_Efficiency (accessed on 11 August 2018).

22. Regulatory, S.R.F.E. 2018 Assessment of Demand Response and Advanced Metering Commission. Nat. Energy 2018. Available online: https:/ / www.ferc.gov/legal/staff-reports/2018/DR-AM-Report2018.pdf (accessed on 11 August 2018).

23. Kopsidas, K.; Galeela, M.M. Utilizing Demand Response to Improve Network Reliability and Ageing Resilience. IEEE Trans. Power Syst. 2018, 34, 2216-2227. [CrossRef]

24. Aalami, H.; Yousefi, G.R.; Parsa Moghadam, M. Demand Response model considering EDRP and TOU programs. In Proceedings of the 2008 IEEE/PES Transmission and Distribution Conference and Exposition, Chicago, IL, USA, 21-24 April 2008; pp. 1-6. [CrossRef]

25. Nikzad, M.; Mozafari, B. Reliability assessment of incentive- and priced-based demand response programs in restructured power systems. Int. J. Electr. Power Energy Syst. 2014, 56, 83-96. [CrossRef]

26. Xia, X.; Setlhaolo, D.; Zhang, J. Residential demand response strategies for South Africa. In Proceedings of the IEEE PES Power Africa 2012-Conference and Exhibition, Johannesburg, South Africa, 9-13 July 2012; pp. 1-6. [CrossRef]

27. Weather Atlas: Monthly Weather Forecast and Climate Freetown, Sierra Leone. Available online: https: / / www.weather-atlas.com (accessed on 11 August 2018).

28. International Energy Agency: Strategic Plan. Available online: http://www.ieadsm.org/strategic-plan (accessed on 8 May 2019).

29. Albadi, M.H.; El-Saadany, E.F. Demand Response in Electricity Markets: An Overview. In Proceedings of the 2007 IEEE Power Engineering Society General Meeting, Tampa, FL, USA, 24-28 June 2007; pp. 1-5. [CrossRef]

30. Federal Energy Regulatory Commission Staff Report: 2012 Assessment of Demand Response and Advanced Metering Staff Report. Available online: https:/ / www.ferc.gov/legal/ (accessed on 10 November 2018).

31. Aalami, H.; Moghaddam, M.P.; Yousefi, G. Demand response modeling considering Interruptible/ Curtailable loads and capacity market programs. Appl. Energy 2010, 87, 243-250. [CrossRef]

32. Asumadu-Sarkodie, S.; Cağlan Sevinç.; Jayaweera, H.M. A hybrid solar photovoltaic-wind turbine-Rankine cycle for electricity generation in Turkish Republic of Northern Cyprus. Cogent Eng. 2016, 3, 1180740. [CrossRef]

33. Sediqi, M.M.; Furukakoi, M.; Lotfy, M.E.; Yona, A.; Senjyu, T. Optimal Economical Sizing of Grid-Connected Hybrid Renewable Energy System. J. Energy Power Eng. 2017, 11. [CrossRef]

34. Electricity Distribution and Supply Authority. Available online: http://www.edsa.sl/ (accessed on 10 December 2018).

35. Ministry of Energy (MoE). Available online: http://www.energy.gov.sl/ (accessed on July 2018).

36. Nikoukar, J. Unit commitment considering the emergency demand response programs and interruptible/ curtailable loads. Turk. J. Electr. Eng. Comput. Sci. 2018, 26, 1069-1080. [CrossRef]

37. Solar Energy for Professionals. Available online: http://www.soda-pro.com (accessed on 5 August 2018).

38. Solano-Peralta, M.; Moner-Girona, M.; van Sark, W.; Vallve, X. “Tropicalisation” of Feed-in Tariffs: A custom-made support scheme for hybrid PV/diesel systems in isolated regions. Renew. Sustain. Energy Rev. 2009, 13, 2279-2294. [CrossRef]

(C) 2019 by the authors. Licensee MDPI, Basel, Switzerland. This article is an open access article distributed under the terms and conditions of the Creative Commons Attribution (CC BY) license (http:/ / creativecommons.org/licenses/by/4.0/). 